\title{
MACHADO, Ana Maria. Um mapa todo seu. Rio de Janeiro: Objetiva, 2015. 222 p.
}

AMANDA DA SILVA OLIVEIRA

Universidade Federal de Santa Maria (UFSM). Santa Maria, RS, Brasil.

Ana Maria Machado talvez achou que teria como problema o fato de que, ao escrever esse romance, houvesse a impossibilidade do ineditismo de um tema histórico, romanceado para a literatura. No entanto, ao ler as páginas do romance Um mapa todo seu, o leitor pode encontrar talvez outras impossibilidades, e não é de um protagonismo feminino em meio social em pleno final do século XIX e início do XX, mas a de poder ter direito ao empoderamento e à afetividade, sem que um não negue a conquista do outro. Para tanto, não são as histórias da vida de grandes nomes da história de nossa cultura política que a autora nos apresenta, nas figuras de Eufrásia Leite e Joaquim Nabuco, mas a intimidade de Zizinha e de Quincas, dois jovens que se relacionam amorosamente, apesar dos padrões sociais que ousam descontruir, mesmo que amarrados às inúmeras exigências da época.

Eufrásia Teixeira Leite é uma jovem herdeira de pouco mais de vinte anos, que tem na orfandade precoce a sorte de poder ser dona do próprio nariz. Junto com a irmã mais velha, Francisca, ousa confrontar a família, representada pelo tio, o barão de Vassouras, a seguirem sozinhas com os negócios deixados pelo pai, e depois pela avó, a baronesa de Campo Belo, e viverem em Paris. A visão da família é incompreensível e autoritária, evidenciando a necessidade impositiva de as irmãs se casarem, para que os maridos possam dar direcionamentos aos bens deixados pela morte do pai comerciante. No entanto, Zizinha, educada e preparada pelo pai para conduzir a herança de forma autônoma e competente, não aceita a imposição do tio e enfrenta a família, mudandose, junto com a irmã e uma dama de companhia, para a capital francesa.

É na viagem à Europa que ela conhece Quincas, jovem que também está a caminho do Velho Mundo para conhecer a cultura, a arte, e poder se encontrar como sujeito. Apaixonam-se instantaneamente, e aproveitam o espaço limitado do navio para intermináveis encontros e conversas, descobrindo inúmeras semelhanças e pontos de vista bastante parecidos. Tudo estaria perfeito se não fosse a irmã da moça, que reforça constantemente a mentira contada aos tios para fugirem de possíveis casamentos com os primos, de que juraram no leito de morte do pai que elas jamais se casariam. Zizinha, muito interessada em Quincas, vive entre o amor recém-descoberto e os maus humores e as más vontades da irmã Chica, que não se mostra nada receptiva ao namoro da irmã mais nova, e acusa Quincas de aproveitador sedutor.

A recusa da imagem e da postura de Quincas da irmã, inicialmente, e, depois, pela visão social de amigos, conhecidos e contatos próximos, contribuem para o peso da moralidade e das conveniências sociais para o romance de Zizinha, e a relação dos dois se prolonga por anos, entre términos e reatamentos, em função das negativas da moça em contrair matrimônio. O jovem Quincas não se comporta como espera a namorada e a possibilidade de perder a liberdade conquistada pela dor da perda dos pais despertam em Zizinha o medo do matrimônio, pois este significa as perdas de autonomia que possui e de comando dos negócios herdados. A consciência de Zizinha é clara: sabe que corresponde a uma pequena parcela de mulheres que podem conduzir a vida sem a presença masculina, mas também compreende que o amor que sente por Quincas pode arruinar os planos de seguir livre, sem depender da ajuda - e das posses - masculina.

Joaquim Nabuco é filho do senador Nabuco de Araújo, mas só adota o sobrenome do pai com a morte desse, anos mais tarde. Ao conhecer Zizinha, na coincidente viagem dos dois à Europa a bordo do Chimborazo, era chamado de Quincas, o belo. Conquistador de inúmeros romances e aventuras amorosas, com as mais bonitas mulheres do país e do mundo - solteiras e casadas, vale ressaltar-, o jovem Quincas parte para a Europa em busca de novas experiências e conhecendo inéditos territórios, o filho do senador vendeu a pouca herança que recebera da madrinha para poder custear a viagem, sonho de muitos anos.

O encontro com Zizinha se dá ao acaso, e potencializa a alegria do rapaz em perceber que a viagem, de fato, fará a ele muito bem. As semelhanças de pensamento entre os dois o encantam, e é impossível a ele resistir 
aos encantos de Zizinha. Fica admirado que ela concorde com ele quanto às questões e aos ideários abolicionistas, e se surpreende quando ela conta que o pai, muito antes de morrer, havia alforriado todos os escravos que possuía de herança. Zizinha era uma mulher educada e muito encantadora, mas pensava sozinha e tinha como meta levar adiante os negócios herdados pelo pai, o que lhe surpreendia, mas também o despertava como desejoso de estar ao lado dela sempre, como que para protegê-la e segui-la pelos espaços europeus então desconhecidos aos dois.

A recusa de Zizinha ao casamento, resultado de mexericos de que estaria flertando com outras moças, deixa Quincas bastante frustrado, pois não consegue conceber a impossibilidade de casamento com ele, desejo de tantas outras mulheres. A pressão estabelecida pela irmã dela confronta com a imagem social de dândi que sua figura representa na sociedade, e seus ideais políticos libertários a favor do abolicionismo da escravatura brasileira passam a torná-lo uma persona non grata nos círculos sociais mais altos. Ao lutar pela causa de libertação dos escravos, percebe que seu romance com Zizinha se coloca em um espaço perigoso e cheio de dificuldades, mas a incapacidade da moça de se curvar a ele, como esposa, pesa mais em seu ego. Dessa forma, fica na inconstância entre a carreira política, dificultada pela posição politica que possui, e a vida amorosa, também complicada pelas posturas censuradas da noiva.

Não há como ler a obra de Ana Maria Machado e não pensar no seu título, e na possível intertextualidade que ele pode conter. Zizinha busca, através da viagem à Europa, um mapa diferente e todo seu a ser traçado, conquistado e habitado. Nesse sentido, e tendo consciência de que sua nova vida incomum à grande maioria das mulheres de sua condição e idade, a personagem parece estar na mesma dimensão crítica da qual Virgínia Woolf sugere em seu ensaio Um teto todo seu. Se a autora britânica, nas linhas de seu texto, refletia sobre a posição da mulher na sociedade e na escrita literária, principalmente na importância de um espaço específico para o encontro da arte e da liberdade criadora, a personagem de Ana Maria Machado parece buscar, nas terras europeias, a efetiva liberdade que pode se sustentar sua autonomia. No entanto, essa liberdade estará sempre fadada aos graus de afetividade e de intimidade com um homem, evidenciando que a mulher não pode ter os dois. Para Zizinha, é essa escolha que a reprime por toda a vida amorosa.

A atmosfera evidenciada pela autora de Um mapa todo seu é marcada sempre pela escolha de autonomia versus casamento, e compromete a vida de Zizinha, que passa a vida entre a indecisão de se entregar ao amor sentido por Quincas, e, com isso, a consequente também entrega das decisões de seus bens. Apesar de a figura feminina que ousa contrariar o modus operandi da família, e multiplicar as heranças do pai e da avó, ela não pode se envolver satisfatoriamente com o amado, pois isso não só significa o aprisionamento social e a perda da emancipação financeira, assim como a imagem pessoal manchada, pois o pretendente é odiado pelos círculos sociais pelos quais transita e atua. Mesmo com as mostras de autossuficiência financeira da personagem, Eufrásia é aprisionada pelas questões morais da época, que julgam seu posicionamento superior e autossuficiente à imagem de aproveitador e caçador de dotes de Joaquim Nabuco. Por mais que a conquista de teto e de mapa sejam todos alcançados por ela, a dependência emocional aos padrões socialmente impostos interfere na vida pessoal da personagem, que acaba por não se decidir entre assumir o romance ou se submeter aos caprichos sociais, bem simbolizados pela irmã mais velha. Aos fins do século XIX e inícios do século XX, até cabia a uma mulher a sorte da independência financeira, da liberdade da própria vida; mas tanta liberdade não lhe permitia usufruir disso tudo com quem bem entendesse.

Assim como Zizinha sofre com os resultados de como a sociedade se organiza e se estrutura, também Quincas segue ao mesmo pressuposto. Se a amada não consegue decidir entre ele e a irmã, enfrentando a tudo e todos para que fiquem juntos, o que o faz romper seriamente com ela, Nabuco tampouco consegue levar adiante seus ideias libertários na organização político-social que se apresenta no Brasil. Apesar da perspectiva revolucionária de dar fim à escravatura em solo brasileiro, porque tem a experiência europeia nas discussões e efetiva realização dessa justiça social, não encontra espaço de consolidação dessas ideias, o que se reforça pela imagem que a sociedade tem dele de um caça-dotes.

Os planos abolicionistas são massacrados diante das sucessivas investidas em cargos públicos em eleições, várias vezes canceladas por denúncias de fraude. Ao mesmo tempo em que as convicções politicas são abaladas pelas agruras que o sistema lhe estabelece, Quincas não pode ter ao lado o amor da mulher que escolheu casar, e a morte do pai confronta com a necessidade de seguir a vida no Brasil, o que mais os distancia. Por mais que os caminhos trilhados por eles entre Brasil e Europa sejam facilmente vencidos pelos navios da época, o que os afastavam eram as ideologias diferentes em que ambos se encontravam. Por mais que Quincas compreendesse e admirasse a riqueza de Zizinha e seu talento para os negócios, incoerentemente não compreendia os motivos que a levavam não abrir mão de tudo em nome do amor dos dois, e considerava falta de confiança da parte dela o fato de não querer deixar ao marido a posse dos seus bens. A narrativa evidencia o quanto as ideias abolicionistas de Nabuco não eram levadas em conta quando 
a liberdade se tratava da própria mulher, o que o leva inúmeras vezes acusar Zizinha de ser egoísta e não o querer bem.

Os finais felizes dos dois personagens são uma mostra ao leitor de como podemos encarar as posições sociais em se tratando de sua ótica de gênero. Eufrásia morre com oitenta anos, riquíssima, mas sozinha, sem herdeiros diretos. Nabuco conquista a alforria dos escravos por meio da lei assinada pela Princesa Isabel, em 1888, vira um dos heróis da abolição e se casa com uma jovem mulher, com quem tem filhos. Se as histórias dos dois apaixonados são tão interessantes em separado, juntas evidenciam o quanto o amor pode se tornar uma opção impossível de ser alcançada quando outros interesses, como a liberdade e os ideais, estão em jogo. Ana Maria Machado evidenciou que o seu romance não poderia ser inédito, posto que envolvia atores sociais históricos de nossa constituição cultural. Mas conquistou um ineditismo cativante ao nos relacionarmos com Zizinha e Quincas, dois jovens com o mundo a sua frente e as inúmeras possibilidades que ele poderia oferecer, e não Eufrásia e Nabuco, nomes da História do Brasil. Sem dúvidas, o romance se insere como uma nova forma de ver a formação da nossa identidade, mas também várias heranças injustas e tão naturalmente enraizadas: as perdas que a emancipação feminina gera e as dificuldades da conquista pela liberdade de todos.

Recebido: $21 / 11 / 2018$

Aprovado: 07/12/2018

Autora:

AMANDA DA SILVA OLIVEIRA

Professora. Universidade Federal de Santa Maria (UFSM).

Santa Maria, RS, Brasil.

profeamandaoliveira@gmail.com 